\title{
Vasectomy and its reversal
}

\author{
Neil T Dwyer BSc MD, John E Grantmyre MD FRCSC
}

NT Dwyer, JE Grantmyre. Vasectomy and its reversal. J Sex Reprod Med 2002;2(4):144-150.

A vasectomy is the contraceptive method of choice for $7 \%$ of American couples. With more than 500,000 vasectomies performed yearly in the United States, it is a procedure that is shared by several fields of medicine. The variety of techniques, their successes and their complication rates make the vasectomy anything but a basic procedure. Considering this, the common goal of a vasectomy is male sterilization.

The vasectomy reversal is a highly specialized procedure that requires considerable microsurgical training. There are several preoperative, intraoperative and postoperative decisions that may affect the overall success of the procedure and the main goal, which is pregnancy. Urologists may find themselves at either end of the fertility spectrum. The present review discusses the vasectomy procedure, surgical techniques and how to manage the outcomes. In addition, vasectomy reversal and its increasing success in the era of intracytoplasmic sperm injection are discussed.

Key Words: Male Infertility; Vasectomy; Vasectomy reversal; Vasoepididymostomy; Vasovasostomy

\section{La vasectomie et sa réversibilité}

RÉSUMÉ : Sept pour cent des couples américains choisissent la vasectomie comme méthode de contraception. Plus de 500000 vasectomies sont pratiquées chaque année aux États-Unis; l'intervention touche donc à plusieurs champs de la médecine. La vasectomie n'est pas une simple opération, loin de là, avec ses différentes techniques, ses taux de réussite et ses taux de complication. Quelle que soit la variante utilisée, il s'agit essentiellement d'un moyen de stérilisation chez les hommes.

Quant à la reperméabilisation des canaux déférents, c'est une opération extrêmement délicate, qui exige une importante formation en microchirurgie. Plusieurs décisions susceptibles de se répercuter sur la réussite globale de l'intervention et sur son objectif principal, la grossesse, doivent être prises avant, pendant et après l'opération. Les urologues peuvent se trouver devant des patients qui situent à l'une ou l'autre des extrémités du spectre de la fertilité. Le présent article traite de la vasectomie comme telle, des techniques chirurgicales et du traitement des résultats. Il sera également question de la réversibilité de la vasectomie et de son taux de réussite de plus en plus élevé à l'ère de l'injection intracytoplasmique de sperme.
$\mathrm{T}$ here are an estimated 500,000 vasectomies performed in the United States yearly. Ninety-three per cent of practising urologists perform vasectomies, and they account for $76 \%$ of the total number of vasectomies that are carried out. The remainder are performed by family practitioners and general surgeons (1). The vasectomy has come a long way since its first description by Cooper in 1830 , with his experiments on canines (2). Today, it is the method of permanent contraception that is preferred by $7 \%$ of couples. Although it is less expensive, and results in lower morbidi- ty and mortality than does tubal ligation, it is still less popular than tubal ligation worldwide (3).

The increasing rate of vasectomy reversals is associated with the ease and popularity of receiving a vasectomy. Up to $6 \%$ of men who have had a vasectomy will return to request a reversal. The divorce rate is $50 \%$, which may be a contributing factor to the increase in vasectomy reversals, as are being younger than 30 years of age at the time of the vasectomy and having had a wife who worked outside of the home $(4,5)$. There was a $69 \%$ increase in reversals when

Department of Urology, Dalhousie University, Halifax, Nova Scotia

Correspondence and reprints: Dr John E Grantmyre, 5991 Spring Garden Road, Suite 332, Halifax, Nova Scotia B3H 1 Y6.

Telephone 902-420-0044, fax 902-420-0240, e-mail john.grantmyre@dal.ca 
comparing men who had a vasectomy from 1980 to 1984 with those who had a vasectomy from 1994 to 1996. There is also an increase in vasectomy reversal requests in men aged 30 to 49 years (5). The present review examines the technical aspects, complications and outcomes of a vasectomy and vasectomy reversal. The feasibility of a vasectomy reversal is examined in view of increasing female age and latency from vasectomy, and the availability of intracytoplasmic sperm injection.

\section{VASECTOMY}

As with most surgical procedures, the first steps are to counsel the patient and to obtain his consent. Because most men having a vasectomy are otherwise healthy, it is imperative to explain in detail the purpose, method and goal of the procedure. Mainly, it is a permanent form of sterilization. Most patients present after having numerous discussions with their friends and after reviewing various sources of literature. The most prevalent source at the authors' centre is the Internet. Many of the surgeons use specialized information and consent forms as opposed to the standard one, when performing vasectomies. This allows for a more detailed discussion concerning the early and late risks and complications of a vasectomy. The authors' preoperative handout describes the procedure and the preparation that is required by the patient regarding eating, drinking, shaving the scrotum, etc. It reinforces the postoperative care with regard to ice packs, activity and the use of alternate forms of contraception until a semen sample has been analyzed.

Local anesthesia is usually adequate for a vasectomy. One to two per cent plain lidocaine injected by using the three-finger technique described by Li (6) in 1992 is the most common method. The three-finger method permits an excellent external spermatic sheath block and allows for the vasectomy to become an outpatient procedure performed under local anesthesia $(1,6)$. The authors add $1 \mathrm{~mL}$ of bicarbonate to $9 \mathrm{~mL}$ of $1 \%$ lidocaine and use a 27 gauge needle when administering the local anesthetic. A slower injection with the smaller needle takes a little longer, but optimizes patient comfort. In addition, the authors inject $0.5 \mathrm{~mL}$ of $0.25 \%$ bupivacaine in the urethral end of the vas deferens at the end of the surgery. Our patients find this beneficial because it provides them with a longer vasal block and allows them to return home in comfort. Nonneedle methods such as the Madajet (Mada Inc, USA) have been investigated and reported, but are not common practice (7). If the patient is anxious, sedating medication can be given orally or intravenously. The authors reserve general anesthesia for extremely anxious patients or difficult anatomy.

There are multiple methods of performing the vasectomy. The standard incision is the most common method in the United States, with the 'no scalpel' technique accounting for 29\% of vasectomies from a 1995 survey by Haws (1). At Dalhousie University, Halifax, Nova Scotia, a survey of urologists showed that, while all surgeons use the 'no scalpel' instruments, $80 \%$ continue to incise the skin with a scalpel. Developed in China, the 'no scalpel' technique was a successful attempt to increase the popularity and ease of performing a vasectomy. The 'no scalpel' method was introduced to North America in 1985 by Li and Goldstein (8) and its popularity has been growing since then. It offers several advantages over the standard technique. A standard vasectomy has a reported hematoma rate of approximately $2 \%$ and an infection rate of $3.4 \%$. The 'no scalpel' method reduces the risks to $0.09 \%$ and $0.91 \%$ for hematoma and infection, respectively. In addition, several studies have reported shorter operative times, less bleeding and less intraoperative and postoperative pain $(8,9)$. The learning curve for 'no scalpel' vasectomy is short, and experienced vasectomists require 15 to 20 procedures to develop proficiency (8).

Once the vas deferens is isolated, there are several options for occluding the lumen, including ligation, cautery, clipping, proximal facial interposition and openended techniques. Haws' survey in 1995 showed that the most common methods in practice were ligation and cautery $(38.4 \%)$, ligation only $(18.4 \%)$, cautery only $(17.6 \%)$, cautery and clips $(14.5 \%)$, clips only $(8.9 \%)$ and ligation and clips (2.2\%). Fascial interposition was looked at separately and it was found that $48.2 \%$ used this method, with urologists and family physicians using it fairly equivalently, while general surgeons tended not to use it (1). Although suture ligature is the most common method, it is associated with necrosis and sloughing of the cut end distal to the suture. The recanalization and vasectomy failure rate with this method is $1 \%$ to $5 \%$. If two medium hemoclips are used on both vasal ends, the failure rate drops to less then $1 \%$. When cautery is used to destroy the lumen of the vas deferens and the transmural segment is spared, the vasectomy failure rate declines to less then $0.5 \%$ (3). Schmidt (10) reported on 6248 vasectomy cases in which he sectioned the vas deferens, fulgurated the lumen and performed fascial interposition of the urethral end of the vas deferens as his occlusive method. He reported no failures as defined by unwanted pregnancy or the persistence of sperm in the semen. These patients were reviewed retrospectively and no active follow-up was undertaken (10). Fascial interposition has never been reviewed in a controlled fashion. It was introduced as a way to decrease vasectomy failure rates, but its more extensive dissection may complicate or increase the operative time of a vasectomy. Goldstein (3) recommended the removal of a $1 \mathrm{~cm}$ segment of the vas deferens, intraluminal thermal cautery with a battery driven cautery, and a medium hemoclip on each end of the vas deferens. It is obvious that there are many options to obtaining adequate vasal occlusion. Table 1 describes the present authors' version of the 'perfect vasectomy'.

After the vasectomy, all the authors' patients convalesce briefly in a recovery room with an ice pack before being discharged to the care of their drivers. The hospital policy at Dalhousie University dictates that all vasectomy patients must have a ride home (public transport will not suffice) regardless of the method of anesthesia. For medicolegal rea- 
TABLE 1

The authors' version of the 'perfect vasectomy'

No scalpel - four instruments
$9 \mathrm{~cm}^{3} 1 \%$ lidocaine with $1 \mathrm{~cm}^{3}$ bicarbonate
$3 \mathrm{~cm}^{3} 0.25 \%$ bupivacaine
$27 \mathrm{~g}$ needle and slow injection
Puncture before or after fixation
Clips with minimal $(0.5 \mathrm{~cm})$ excision of vas deferens
No cautery
No fascial interposition
No skin closure
Single semen analysis in three months

sons, the authors believe that 'in office' vasectomy patients should be given the same advice.

Patients are fully counselled about providing a semen sample in three months and considering themselves to be fertile until their urologist tells them otherwise. If the first sample is positive for sperm, the authors advise the patient to continue alternate forms of birth control and to provide a second specimen in one month's time. There are many variations among centres for the timing and quantity of semen samples. A study by Badrakumar et al (11) in 2000 examined this exact issue. They took 1321 men who were having a vasectomy and divided them into two groups: group 1 (961 men) were asked for one semen sample at four months, whereas group 2 (360 men) had to provide a semen sample at three and four months postvasectomy. Of the 960 men in group 1, $810(84 \%)$ patients provided a sample at four months and $97 \%$ of them were sperm-free; 21 of the remaining 27 men produced a negative sample within the next seven months and were declared to be azoospermic. Thus, overall in group 1, 84\% of the men became azoospermic. In group 2, 294 (82\%) men provided a sample at three months and only 259 (72\%) gave a sample at four months. Ninety-eight per cent of the men who gave the three month sample were declared azoospermic and 97\% were azoospermic after the sample at four months (11). This study (11) confirmed that the practice of obtaining one semen sample at three months postvasectomy is enough to declare azoospermia and has a higher compliance ratio compared with requesting multiple samples. The Haws survey (1) showed that a timed specimen at six weeks is the most common practice used by $34 \%$ of the physicians who participated in the survey. Urologists have looked at ways to speed the clearing of sperm from the vas deferens to aid in decreasing the time from surgery to infertility. Mason et al (12) examined sterile water irrigation of the distal vas deferens at vasectomy in a prospective randomized trial. They found that there was no significant difference between the two groups and that vasal irrigation offered no benefit (12).

One question that men who request a vasectomy usually ask is, "What happens if there is still sperm in the semen in the postvasectomy analysis?" Vasectomy failure can be divided into two categories - early and late. Early vasectomy failure is when the patient's semen never clears of sperm from the initial analysis, and it is due mainly to spontaneous recanalization of the vas deferens and, less commonly, to inadvertent double vasectomy on one side. Motile sperm should be present for about three weeks after the procedure and, if present, indicates that the vasectomy has failed. Special clearance can be given if the patient is more than seven months from surgery and has two consecutive sperm counts showing nonmotile sperm in concentrations of less then $10,000 / \mathrm{mL}$. Davis et al (13) examined the same subject but did not subcategorize according to motile and nonmotile sperm and found that, if the same criteria were used, no pregnancies resulted. Late vasectomy failure can happen at any time and is usually discovered by an unplanned pregnancy. The quoted failure rate is one/2000 vasectomies and is thought to be secondary to the proliferation of micro channels that transport sperm. Occasionally, sperm reappear in the ejaculate after the vasectomy has been cleared. To investigate the significance of this phenomenon, one study followed men, after their vasectomies, for three years. After the vasectomies, the men underwent a semen analysis at 16 and 18 weeks, and as long as both specimens were negative, the patients were included in the study. They were asked to provide a semen sample at one, two and three years after the vasectomy. At reporting, there were 2250 men past one year -1400 of the men were at two years and 1000 were at three years postvasectomy. There were 20 men with positive semen analyses (year $1=15$; year $2=4$; year $3=1$ ). None of the second- or third-year positive tests had ever had a previous positive test. The sperm count was less than $10,000 / \mathrm{mL}$ in 17 of the 20 cases, and 14 of those cases provided a negative semen sample one month later. There were no unwanted pregnancies and only one patient with a positive test had persistently high sperm counts and was advised to have a repeat vasectomy. This study showed there was a $0.9 \%$ rate of positive semen analysis as a late reoccurrence and only one of 2250 men required a repeat vasectomy. These numbers are consistent with those suggested previously (14).

Some of the complications of a vasectomy, specifically hematoma and infection, have already been discussed in the description of the various techniques. A sperm granuloma can form at the testicular end of the vas deferens. The sperm leak out of the vas deferens and, due to their antigenicity, they cause an inflammatory reaction. Clinically, this may become apparent to patients as a pea-sized lump in the area of the operation. A possible benefit of a sperm granuloma is the venting of the testicular end of the vas deferens, which may minimize damage to the seminiferous tubules and epididymis. This may play a role if the patient ever undergoes a vasectomy reversal, but this has never been definitively proven. The presence of a sperm granuloma can be expected in up to $33 \%$ of the patients, but removal of the granuloma has only been shown to be beneficial if a patient has persistent and irritating discomfort localized to the site (3). 
Chronic testicular pain after a vasectomy has been described. The incidence from reported studies varies from $0 \%$ to $70 \%$. McMahon et al (15) reported on 172 men four years after a traditional vasectomy. Thirty-three per cent described chronic testicular discomfort, while $15 \%$ found it troublesome and only 5\% sought medical attention. Two patients underwent a secondary surgical procedure to deal with the pain. At the present authors' institution, complications including chronic testicular pain after vasectomy were examined using the 'no scalpel' technique. By using a postal survey, replies were obtained from 219 of the 443 surveys mailed. Twenty-four per cent of the patients described chronic testicular pain, 15\% stated that it was 'no trouble', $7 \%$ said the pain was a 'nuisance', and $2 \%$ claimed that the pain was severe. In addition, $2 \%$ of the respondents said that they experienced testicular pain frequently with intercourse. Seven per cent sought medical attention and only one patient required surgery to relieve the pain (16).

Overall, a similar number of patients from both techniques have chronic testicular pain. The increase in the number of patients seeking medical attention may be secondary to the difference in the medical systems involved and the changing climate of patient care.

Vasectomy has been examined as a causative link to prostate cancer, cardiovascular risk and immune complexmediated diseases. There have been numerous reports dismissing any causative link and patients can be informed with confidence that a vasectomy is not knowingly associated with any systemic illness (3,17-19).

\section{VASECTOMY REVERSAL}

As mentioned, it is estimated that up to $6 \%$ of men who undergo a vasectomy will return and request a reversal. At this point, the urologist is faced with the task of reversing a 'permanent' form of sterilization. Unlike a vasectomy, a reversal should be performed by an expert in the area of male infertility who performs microsurgery on a regular basis. There are numerous factors to consider, ranging from the time since the vasectomy, the partner's age and the method of reversal. Generally, a vasectomy reversal refers to a vasovasostomy $(\mathrm{VV})$, but certain patients may require a vasoepididymostomy (VE), depending on the operative findings.

Patients requesting a vasectomy reversal commonly ask their urologist, "should I get a reversal or should we just go for in vitro fertilization?" (IVF). This is an obvious question with the recent popularity and availability of intracytoplasmic sperm injection (ICSI). Some proponents of ICSI have suggested its use for all types of male infertility. The authors feel that this is a costly approach that carries an increased risk of multiple births and possibly a higher risk of birth defects when a suitable safe treatment is available. When factors such as maternal age, sex of the infant and correlation with siblings are considered, ICSI and IVF are twice as likely as natural conception to produce a child with a major birth defect (20). Cost is another huge concern, because ICSI, IVF and VV are often not covered by health plans and the money comes directly from the couple who is trying to conceive. Several reports have confirmed that the costbenefit ratio favours VV over ICSI and IVF. Heidenreich et al (21) compared the cost, success and complications of VV for vasectomy reversal with microsurgical sperm aspiration (MESA), testicular extraction of sperm (TESE) and ICSI for epididymal obstruction and azoospermia of testicular origin. One hundred fifty-seven VVs were performed by using the double-layer technique, with a patency of $77 \%$ and a pregnancy rate of $52 \%$. Sixty-nine couples underwent MESA and/or ICSI and 42 couples had TESE and/or ICSI, for pregnancy rates of $22.5 \%$ and $19.5 \%$, respectively. The VV group had a local complication rate of $4.7 \%$ and no major complications. The MESA/TESE and ICSI group had a local complication rate of $3.9 \%$ in the men, while $7.9 \%$ of the women experienced mild to severe ovarian hyperstimulation syndrome. The cost per live birth for the VV group was $€ 2793$, whereas the cost per live birth after a MESA/TESE cycle was $€ 14,547$. As well, multiple births occurred $15.8 \%$ of the time with ICSI and only $0.7 \%$ of the time with VV. Thus, VV has a higher success rate and fewer complications and is more cost efficient then MESA and/or TESE with ICSI. The standard treatment for obstructive azoospermia after a vasectomy should be a vasectomy reversal (21).

The success of a VV is dependent on a number of factors, with surgeon experience and time since vasectomy being the most important. The surgeon's experience is controlled for by limiting this treatment to a subset of specially trained urologists. When considering a vasectomy reversal and the interval is three years or less since the vasectomy, the patency rate is $97 \%$, with a pregnancy rate of $76 \%$. From three to eight years after a vasectomy, the patency rate is $88 \%$ and the pregnancy rate is $53 \%$. From nine to 14 years, the patency rate is $79 \%$ and the pregnancy rate is $44 \%$, and this drops to a $71 \%$ patency with a $30 \%$ pregnancy rate for reversals when 15 years or longer have passed since the vasectomy (22). Fuchs and Burt (22) examined the vasectomy reversal success rates in patients for whom the vasectomy was 15 years earlier and who were subcategorized for female age, and they compared these results with published ICSI results. There were 116 eligible patients and $62 \%$ of those men required bilateral $\mathrm{VE}$ or a unilateral $\mathrm{VV}$ with a contralateral VE. The VV only group had a $90 \%$ patency with a $43 \%$ pregnancy rate, compared with $86 \%$ patency and a $47 \%$ pregnancy rate in the group with bilateral or unilateral VE. Overall, the patency rate was $85 \%$, with a pregnancy rate of $43 \%$ and a live birth rate of $36 \%$. When they examined the interval since vasectomy, the patients who underwent vasectomies 15 to 19 years earlier had a patency of $89 \%$, a pregnancy rate of $49 \%$ and a live birth rate of $39 \%$. Patients who underwent vasectomies 20 to 25 years earlier had patency rates of $78 \%$, pregnancy rates of $33 \%$ and live birth rates of $31 \%$. Fuchs and Burt also examined the age of the female partner and found that, if they stratified the women into two groups (younger than 36 years of age and 36 years of age and older), the pregnancy rates were 


\section{TABLE 2}

Relationship between gross appearance of vasal fluid and microscopic findings

\begin{tabular}{lll}
\hline Vasal fluid appearance & $\begin{array}{l}\text { Most common findings } \\
\text { on microscopic examination }\end{array}$ & $\begin{array}{l}\text { Surgical procedure } \\
\text { indicated }\end{array}$ \\
\hline Copious, crystal clear, watery & No sperm in fluid & Vasovasostomy \\
$\begin{array}{l}\text { Copious, cloudy, thin, water soluble } \\
\text { Copious, creamy, yellow }\end{array}$ & Intact sperm & Vasovasostomy \\
$\begin{array}{l}\text { Copious, thick, white } \\
\text { Scant, white, thin }\end{array}$ & Sperm heads and tails & Vasovasostomy \\
$\begin{array}{l}\text { Dry vas deferens with no associated granuloma } \\
\text { at the vasectomy site }\end{array}$ & No sperm & No sperm \\
$\begin{array}{l}\text { Dry vas deferens with granuloma at } \\
\text { the vasectomy site }\end{array}$ & No sperm & Vasoepididymostomy \\
\end{tabular}

Adapted from reference 39

$54 \%$ and $31 \%$, and the birth rates were $48 \%$ and $24 \%$, respectively. When considering the success of ICSI in couples who suffer with male factor infertility secondary to obstructive azoospermia, the pregnancy rate is $40 \%$, with a live birth rate of $27 \%$. Thus, vasectomy reversal is a valid option when more than 15 years of obstructive azoospermia has occurred and in cases in which there is advanced female age (23). Even if the maternal age averages 40 years, the cost per newborn with vasectomy reversal is US $\$ 28,530$ versus the cost per newborn in women older than 36 years of age using ICSI, which is is US $\$ 103,940$ (24). Vasectomy reversal is safer than ICSI, has similar to better results than ICSI (even in patients with a partner's age of more than 36 years), and is less costly than ICSI. If couples have male factor infertility secondary to a previous vasectomy and the woman is ovulating, vasectomy reversal should be the primary treatment option.

As a matter of policy, the present authors offer sperm retrieval to all patients undergoing a vasectomy reversal, but they recommend it to patients whose vasectomies were more than 15 years earlier, or when the woman is older than 36 years of age or if she has a history of tubal disease. If the couple decides to have sperm retrieval, the authors take it from the vas deferens, then the epididymis, and then the testicle, provided that motile sperm are seen. If a $\mathrm{VV}$ is performed and the fluid contains nonmotile sperm, the authors go to the testicle for the biopsy and sperm retrieval so as to not jeopardize the VV by causing injury to the epididymis. Glazier et al (25) followed the outcome of cryopreserved sperm obtained during a vasectomy reversal and found that $14.6 \%$ of the couples used the sperm. The most common reasons for the use of the cryopreserved sperm were postoperative azoospermia and/or severe oligospermia and wives who were approaching 40 years of age. The average time to pregnancy after vasectomy reversal was one year, which is consistent with previously reported data $(22,25)$. This is important when advising couples regarding vasectomy reversal and sperm cyropreservation, because if the operation is not a success, it may take more than a year for the couple to recognize this and, unfortunately, the maternal age continues to climb.

A vasectomy reversal can be performed under local anesthesia, but this method has several disadvantages compared with a general anesthetic. Obviously, even small movements can be disruptive under an operating microscope at powers up to 26 times magnification. In addition, a general anesthetic allows for the delivery of the testicle, repair of a large vasal gap and a VE, which may take 3 to $4 \mathrm{~h}$. There is plenty of evidence to support the use of an operating microscope when performing a VV or a VE. The operating microscope offers higher patency and pregnancy rates than optical loupe magnification or the macroscopic technique (26-31). The authors use the modified one-layer technique (9-0 suture) routinely when performing VVs. Some centres are proponents of the two-layer technique, but the present authors believe that it offers no advantage and is more time consuming than the one-layer technique $(22,29)$. Fischer and Grantmyre (31) compared the patency rates of 40 men, 17 of whom underwent the modified one-layer VV and 23 of whom had the two-layer VV (10-0 suture on the inside and $9-0$ for the outside). The mean operative time was 96 min for the modified one-layer VV compared with $167 \mathrm{~min}$ for the two-layer VV. The patency rates were equivalent at $88 \%$ and $90 \%$, respectively (31). The present authors occasionally use the two-layer technique if the anastomosis involves the convoluted portion of the vas deferens or if the luminal diameters are grossly different.

The intraoperative decision of whether to perform a VV or VE depends mainly on gross and microscopic assessment of the vasal fluid. When the testicular side of the vas deferens is divided, the fluid is examined by using a light microscope in the operating room. If the fluid contains sperm, the patency is often greater then $90 \%$, with a pregnancy rate of $60 \%$ to $70 \%$. If only sperm heads are present, the patency rate drops to $75 \%$. If there is no sperm in the fluid, the overall patency rate is $60 \%$, with a pregnancy rate of $30 \%$. The patency is $80 \%$ with a $45 \%$ pregnancy rate if there is no sperm and the fluid is watery; there is $75 \%$ patency if the 
fluid is cloudy; and the patency is only $26 \%$ if the fluid is creamy $(3,22,27)$.

Table 2 offers some recommendations as to when to perform a VV or a VE, depending on the intraoperative vasal fluid findings.

Generally, sperm are present in the cut vasal ends, and no sperm is seen in only $14 \%$ of cases. This number can fluctuate with the latency from vasectomy to vasectomy reversal, with only an $8 \%$ absence of sperm if there are less then five years since the vasectomy, and a $26 \%$ absence of sperm if the vasectomy was performed 11 to 25 years earlier (27). Thus, a minority of patients will require a VE.

A VE is technically more demanding then a VV and requires considerable training in microsurgery. Only a surgeon who is trained and experienced in VE should undertake such a challenge. The surgical options are varied when considering a VE, and the reported patency rates range from $39 \%$ to $100 \%$, with pregnancy rates of $13 \%$ to $42 \%$, when using an end-to-end technique. An end-to-side technique can also be used with similar patency rates $(32,33)$. More recently, a triangulation end-to-side or intussusception method for VE was described with a patency rate of $92 \%$ and a shorter operating time at $156 \mathrm{~min}$ (34). This method was compared with standard end-to-side VE in rats and was shown to have a superior patency rate (35). Further trials in humans are needed to fully evaluate the benefits and success of the intussusception method for VE.

The early complications following vasectomy reversal are nominal, with a low rate of infection and hematoma. One devastating late complication is the late obstruction of the vas deferens after initial patency, which occurs in $12 \%$ of men by 14 months postoperatively (3). Complete failure of a VV is usually secondary to unrecognized epididymal obstruction, whereas a compromised anastomosis is usually the cause of a late failure (33). Several reports have examined the success of repeat vasectomy reversal after initial failure. The patency rates range from $64 \%$ to $79 \%$, with pregnancy rates of $27 \%$ to $43 \%$. Some predictors are the ability to perform a VV on at least one side and the length of time since the vasectomy was perfromed $(33,36,37)$. Pasqualotto et al (38) examined the success of repeat VE and found that of the 18 patients, $66 \%$ achieved patency and 25\% succeeded in natural conception. The patency and pregnancy rates of repeat VV and VE are encouraging and show that offering these surgeries a second time is a reasonable option.

\section{CONCLUSIONS}

The ease and safety of a vasectomy has increased its popularity. It is still less common then tubal ligation as a form of permanent sterilization, but, hopefully, with education and public awareness, its attractiveness will continue to climb. As vasectomies becomes more accepted, it is even more important for the surgeon to have a detailed discussion with every patient regarding the risks and permanent goals of the surgery. Fortunately, vasectomy reversal is becoming increasingly successful with newer techniques and widely available microsurgical training. The concept of 'family planning' has become a dynamic one in our society and, fortunately, we are able to help patients manage their fertility.

\section{REFERENCES}

1. Haws JM, Morgan GT, Pollack AE, Koonin LM, Magnani RJ, Gargiullo PM. Clinical aspects of vasectomies performed in the United States in 1995. Urology 1998;52:685-91.

2. Drake MJ, Mills IW, Cranston D. On the chequered history of vasectomy. BJU Int 1999;84:475-81.

3. Goldstein M. Surgical management of male infertility and other scrotal disorders. In: Walsh PC, Retik AB, Vaughan ED Jr, Wein AJ, eds. Campbell's Urology, 7th edn. Philadelphia: Saunders, 1998:1331-78.

4. Potts JM, Pasqualotto FF, Nelson D, Thomas AJ Jr, Agarwal A. Patient characteristics associated with vasectomy reversal. J Urol 1999;161:1835-9.

5. Holman CD, Wisniewski ZS, Semmens JB, Rouse IL, Bass AJ. Population-based outcomes after 28,246 in-hospital vasectomies and 1,902 vasovasostomies in Western Australia. BJU Int 2000;86:1043-9.

6. Li PS, Li SQ, Schlegel PN, Goldstein M. External spermatic sheath injection for vasal nerve block. Urology 1992;39:173-6.

7. Wilson CL. No-needle anesthetic for no-scalpel vasectomy. Am Fam Phys 2001;63:1295.

8. Li SQ, Goldstein M, Zhu J, Huber D. The no-scalpel vasectomy. J Urol 1991;145:341-4.

9. Sokal D, McMullen S, Gates D, Dominik R. A comparative study of the no scalpel and standard incision approaches to vasectomy in 5 countries. The Male Sterilization Investigator Team. J Urol 1999;162:1621-5.

10. Schmidt SS. Vasectomy by section, luminal fulguration and fascial interposition: Results from 6248 cases. Br J Urol 1995;76:373-4.

11. Badrakumar C, Gogoi NK, Sundaram SK. Semen analysis after vasectomy: When and how many? BJU Int 2000;86:479-81.

12. Mason RG, Dodds L, Swami SK. Sterile water irrigation of the distal

vas deferens at vasectomy: Does it accelerate clearance of sperm? A prospective randomized trial. Urology 2002;59:424-7.

13. Benger JR, Swami SK, Gingell JC. Persistent spermatozoa after vasectomy: A survey of British urologists. Br J Urol 1995;76:376-9.

14. Haldar N, Cranston D, Turner E, MacKenzie I, Guillebaud J. How reliable is a vasectomy? Long-term follow-up of vasectomised men. Lancet 2000;356:43-4.

15. McMahon AJ, Buckley J, Taylor A, Lloyd SN, Deane RF, Kirk D. Chronic testicular pain following vasectomy. Br J Urol 1992;69:188-91.

16. Sitland T, Shuba L, Grantmyre JE. Incidence of chronic pain and erectile dysfunction following the no-scalpel vasectomy. Can J Urol 2001;8:1278. (Abst)

17. Lesko SM, Louik C, Vezina R, Rosenberg L, Shapiro S. Vasectomy and prostate cancer. J Urol 1999;161:1848-52.

18. Bohring C, Krause W. Differences in the antigen pattern recognized by antisperm antibodies in patients with infertility and vasectomy. J Urol 2001;166:1178-80.

19. Coady SA, Sharrett AR, Zheng ZJ, Evans GW, Heiss G. Vasectomy, inflammation, atherosclerosis and long-term follow-up for cardiovascular diseases: No associations in the atherosclerosis risk in communities study. J Urol 2002;167:204-7.

20. Hansen M, Kurinczuk JJ, Bower C, Webb S. The risk of major birth defects after intracytoplasmic sperm injection and in vitro fertilization. N Engl J Med 2002;346:725-30.

21. Heidenreich A, Altmann P, Neubauer S, Engelmann UH. Microsurgical vasovasostomy in the age of modern reproduction medicine. A cost-benefit analysis. Urologe A 2000;39:240-5.

22. Belker AM, Thomas AJ Jr, Fuchs EF, Konnak JW, Sharlip ID. Results of 1,469 microsurgical vasectomy reversals by the Vasovasostomy Study Group. J Urol 1991;145:505-11. 
23. Fuchs EF, Burt RA. Vasectomy reversal performed 15 years or more after vasectomy: Correlation of pregnancy outcome with partner age and with pregnancy results of in vitro fertilization with intracytoplasmic sperm injection. Fertil Steril 2002;77:516-9.

24. Deck AJ, Berger RE. Should vasectomy reversal be performed in men with older female partners? J Urol 2000;163:105-6.

25. Glazier DB, Marmar JL, Mayer E, Gibbs M, Corson SL. The fate of cryopreserved sperm acquired during vasectomy reversals. J Urol 1999;161:463-6.

26. Yarbro ES, Howards SS. Vasovasostomy. Urol Clin North Am 1987; 14:515-26.

27. Belker AM. Vasectomy reversal. Urol Clin North Am 1987;14:155-66.

28. Thomas AJ Jr. Vasoepididymostomy. Urol Clin North Am 1987;14:527-38.

29. Sharlip ID. Vasovasostomy: Comparison of two microsurgical techniques. Urology 1981;17:347-52.

30. Silber SJ. Microsurgery for vasectomy reversal and vasoepididymostomy. Urology 1984;23:505-24.

31. Fischer MA, Grantmyre JE. Comparison of modified one- and twolayer microsurgical vasovasostomy. BJU Int 2000;85:1085-8.

32. Fogdestam I, Fall M. Microsurgical end-to-end and end-to-side epididymovasostomy to correct occlusive azoospermia. Scand J Plast Reconstr Surg 1983;17:137-40.

33. Matthews GJ, McGee KE, Goldstein M. Microsurgical reconstruction following failed vasectomy reversal. J Urol 1997;157:844-6.

34. Berger RE. Triangulation end-to-side vasoepididymostomy. J Urol 1998;159:1951-3.

35. McCallum S, Li PS, Sheynkin Y, Su LM, Chan P, Goldstein M. Comparison of intussusception pull-through end-to-side and conventional end-to-side microsurgical vasoepididymostomy: Prospective randomized controlled study in male wistar rats. J Urol 2002;167:2284-8.

36. Hernandez J, Sabanegh ES. Repeat vasectomy reversal after initial failure: Overall results and predictors for success. J Urol $1999 ; 161: 1153-6$

37. Fox M. Failed vasectomy reversal: Is a further attempt using microsurgery worthwhile? BJU Int 2000;86:474-8.

38. Pasqualotto FF, Agarwal A, Srivastava M, Nelson DR, Thomas AJ Jr. Fertility outcome after repeat vasoepididymostomy. J Urol 1999;162:1626-8.

39. Goldstein M. Vasovasostomy: Surgical approach, decision making, and multiplayer microdot technique. In: Goldstein M, ed. Surgery of Male Infertility. Philadelphia: WB Saunders Co, 1995:51. 